\title{
Prevalence and phylogenetic analysis of tick-borne encephalitis virus (TBEV) in field-collected ticks (Ixodes ricinus) in southern Switzerland
}

\author{
Nadia Rieille ${ }^{1,2^{*}}$, Stéphane Bressanelli ${ }^{3}$, Caio C M Freire ${ }^{4}$, Séverine Arcioni ${ }^{5}$, Lise Gern ${ }^{6}$, Olivier Péter ${ }^{1}$ \\ and Maarten J Voordouw ${ }^{2}$
}

\begin{abstract}
Background: Tick-borne encephalitis is the most common tick-borne viral infection in Europe with 3,000 human cases reported each year. In Western Europe, the castor bean tick, Ixodes ricinus, is the principal vector of the tick-borne encephalitis virus (TBEV). TBEV appears to be spreading geographically and was recently detected for the first time in Canton Valais in the southern part of Switzerland. The purpose of the present study was to survey the I. ricinus tick populations of Canton Valais for TBEV.

Methods: We collected a total of 19,331 I. ricinus ticks at 45 different sites in Canton Valais between 2010 and 2013. Ticks were processed in pools and tested for TBEV using reverse transcription quantitative PCR. The NS5 gene and the envelope gene of the TBEV isolates were partially sequenced for phylogenetic analysis.

Results: TBEV was detected in tick populations at six of the 45 sites. These six sites were all located in a $33 \mathrm{~km}$ transect along the Rhône River. TBEV was detected in two sites for three of the four years of the study showing the temporal persistence of the pathogen. Prevalence of TBEV in the six positive sites ranged from $0.16 \%$ to $11.11 \%$. Phylogenetic analysis found that all TBEV isolates from Canton Valais belonged to the European subtype. Genetic analysis found two distinct lineages of TBEV suggesting that Canton Valais experienced two independent colonization events.
\end{abstract}

Conclusions: TBEV appears to be well established at certain locations in Canton Valais.

Keywords: Envelope protein, Flavivirus, Ixodes ricinus, Switzerland, Tick, Tick-borne encephalitis virus, Tick-borne disease

\section{Background}

Tick-borne encephalitis is the most important viral tickborne disease in Europe [1]. The causative pathogen is a single-stranded RNA virus that belongs to the tick-borne flavivirus group (genus Flavivirus, family Flaviviridae). This family of arboviruses includes dengue and yellow fever virus. The tick-borne encephalitis virus (TBEV) exhibits genetic variation across its geographic range and three subtypes of TBEV are currently recognized: European (TBEV-Eu), Siberian (TBEV-Sib), and Far

\footnotetext{
* Correspondence: nadia.rieille@unine.ch

'Central Institute of Valais Hospitals, Infectious diseases, Av Grand Champsec 86, Sion, Switzerland

${ }^{2}$ Laboratory of Ecology and Evolution of Parasites, Institute of Biology, University of Neuchâtel, Rue Emile-Argand 11, 2000 Neuchâtel, Switzerland

Full list of author information is available at the end of the article
}

Eastern (TBEV-FEa) [2-4]. All three TBEV subtypes attack the central nervous system of the host with potentially fatal outcomes in humans. The European subtype is the least virulent subtype and is responsible for all human cases of TBE in Western Europe.

TBEV is a zoonotic pathogen that is maintained in nature by cycling between competent reservoir hosts and a tick vector. The most important vertebrate reservoir hosts for the virus are small mammals such as rodents [5]. In Western Europe, the main vector of TBEV is the castor bean tick, Ixodes ricinus. This tick has three stages: larva, nymph, and adult and each stage takes a single blood meal from a different host to complete its development to the next stage. Larvae are generally uninfected because transovarial (vertical) transmission of TBEV is rare [6,7]. Larvae (or nymphs) acquire TBEV during the blood meal and 
maintain the infection after molting into the nymphal stage (or adult stage) in a process called transstadial transmission. Once infected, ticks carry the virus for life [8]. From an epidemiological perspective, infected nymphs are the most important stage because they are much more numerous than infected adult ticks.

The proportion (or prevalence) of TBEV-infected ticks in populations of $I$. ricinus is often low. In European areas where TBEV is endemic, the prevalence of the virus in I. ricinus populations varies from 0.1 to $5.0 \%$ [9]. At a spatial scale, the distribution of TBEV-infected ticks and reservoir hosts is highly patchy and these patches are often referred to as foci $[10,11]$. There is substantial temporal variation in the prevalence of TBEV and newly established foci will not necessarily persist through time [12]. Surveillance of TBEV foci is therefore necessary to establish if the risk of infection remains or has disappeared.

Currently, TBE is known to be endemic in Eurasia from Central Europe to Japan [13]. In Europe, 3,000 human cases are reported each year and this number rises to 10,000 cases per year if Russia is included [14]. In recent years, the human case load of TBE appears to be increasing in regions where it had not been previously observed such as Scandinavia [15-18], and France [19] as well as in TBE-endemic areas such as eastern Europe [20]. This increasing human caseload may be explained by several factors including improved diagnosis, climate change (in Northern Europe), and socio-economical changes (in Eastern Europe) [20,21]. In addition, phylogeographic approaches have been used to study the evolutionary history and dispersal of TBEV in Eurasia [22-24]. At the continental scale, TBEV originated in Eastern Europe before spreading westward across the European continent over a period of 2,500 years [22,25]. Studies at finer geographic scales have shown a variety of dispersal patterns associated with both biogenic and anthropogenic factors [23,26].

In Switzerland, TBE in humans was first described in 1969 via serology $[27,28]$. In the following years, TBEV was identified in tick populations from the northeastern and central part of the country [29-32]. During the last decade, the virus and the disease appear to have spread to the western part of Switzerland [33-35]. Phylogenetic analysis of the Swiss isolates found several distinct lineages of the European subtype suggesting multiple introductions of TBEV [33,34]. To date, little is known about the prevalence of TBEV in the southern part of Switzerland including Canton Valais. In 2009, a national survey collected more than 62,000 ticks from all over Switzerland and screened them for TBEV [33]. This survey detected TBEV in 38 areas in Switzerland including two areas in Canton Valais: Raron and Salgesch [33]. This was the first time that TBEV had been reported in the southern part of Switzerland.
The present study further investigates the prevalence of TBEV in $I$. ricinus tick populations in Canton Valais. The first objective of the study was to confirm the persistence of TBEV in Raron and Salgesch, the two risk areas previously identified by the national survey. The second objective was to test other tick populations in Canton Valais for the presence of TBEV. We also conducted a phylogenetic analysis to determine the origin and relatedness of the Valais TBEV isolates. The present study allows us to evaluate the risk of TBE in Canton Valais.

\section{Methods}

\section{Collection of ticks in the field}

The fieldwork was conducted between May 2010 and June 2013. We surveyed the two sites in Canton Valais that had previously been identified as TBEV foci by the national survey: Raron (2.7 ha) and Salgesch (41 ha) [33]. Ticks were also collected from 43 additional sites distributed throughout Canton Valais (see Additional file 1). The dominant criteria for selecting these sites were percent forest cover and road access. Most sites had an elevation between 390 and $1600 \mathrm{~m}$ and the habitat consisted of forest and bushes. We collected ticks by dragging a white cotton towel (surface of $1.0 \mathrm{~m}^{2}$ ) over the vegetation. The towel was inspected for ticks every $10 \mathrm{~m}$ and ticks were identified to the species level using the key by Cotty (1985) [36]. All I. ricinus ticks were brought to the laboratory and stored in tubes at $-80^{\circ} \mathrm{C}$ until further analysis.

\section{Tick pooling and RNA extraction}

Ticks were screened for TBEV using the methods described in Gäumann et al. (2010) [33]. The 19,331 ticks were grouped in 1,033 pools of 10-20 adults or 50 nymphs to increase the efficiency of the screening procedure. Pools of ticks were placed in individual $2 \mathrm{ml}$ micro tubes with $250 \mu \mathrm{l}$ of PBS (0.1 M, pH 7.2) and stored at $2-8^{\circ} \mathrm{C}$. Ticks were crushed by shaking them in the presence of a stainless steel bead ( $7 \mathrm{~mm}$ diameter) at $50 \mathrm{~Hz}$ for 10 minutes using the TissueLyser system (Qiagen). The lysate volume was adjusted with PBS to a final volume of $3.5 \mathrm{ml}$ in a larger tube. After centrifugation ( $2 \mathrm{~min}$ at $960 \mathrm{~g}$ ), $650 \mu \mathrm{l}$ of supernatant from each sample was used for RNA extraction, which was performed using the AmpliPrep COBAS (Roche, Rotkreuz, Switzerland) and Cobas AmpliPrep Total Nucleic Acid Isolation (TNAi) kits. The RNA was eluted in a final volume of $75 \mu \mathrm{l}$ of elution buffer consisting of phosphate buffer, sodium chloride and sodium azide.

One-step reverse transcription quantitative PCR (RT-qPCR) We used reverse transcription quantitative PCR (RT-qPCR) to test whether the 1,033 tick pools were infected with 
TBEV. The RT-qPCR targeted a fragment of the TBEV envelope $(E)$ gene using the primers and probes described by Gäumann et al. (2010) [33]. We amplified the 5 ' non-coding region of the Mengo virus as an internal control for each of the $1,033 \mathrm{RT}-\mathrm{qPCR}$ reactions. An extract of the TBEV vaccine (Baxter, Switzerland) was used as the positive control and distilled water was used as the negative control. Samples were processed in 46 experimental blocks with 20 to 45 samples per block. Each experimental block contained one positive control and one negative control for every five samples. Experimental blocks were considered valid if the internal controls and the positive controls were detected. Samples were considered positive when TBEV was detected before 40 cycles with a threshold of 0.05 fluorescence units. All TBEV-positive samples were retested twice and all such samples tested positive three times. RT-qPCR was performed using the Thermo scientific Verso 1-step QRT-PCR plus Rox kit (Thermo scientific, Surrey, UK).

The RT-qPCR reaction for each pooled tick sample contained $5 \mu \mathrm{l}$ of RNA template and $20 \mu \mathrm{l}$ of master mix. The $20 \mu \mathrm{l}$ master mix contained $12.5 \mu \mathrm{l}$ of 1 -Step QPCR Mix, 1.25 $\mu$ l of QRTase Enhancer, $0.25 \mu \mathrm{l}$ of Verso Enzyme Mix, $4 \mu \mathrm{l}$ of primers $(0.5 \mu \mathrm{M}), 2 \mu \mathrm{l}$ of probes $(0.2 \mu \mathrm{M})$, and $0.02 \mu \mathrm{l}$ of Mengo virus cDNA. The $4 \mu \mathrm{l}$ primers solution contained $1 \mu \mathrm{l}$ of each of the forward (tbeE-F6) and reverse (tbeE-R2) primers targeting the terminal part of the $E$ gene of TBEV and $1 \mu \mathrm{l}$ of each of the forward (Mengo-F1) and reverse (Mengo-R1) primers targeting the 5' non-coding region of the Mengo virus (see Additional file 2). The $2 \mu \mathrm{l}$ probes solution contained $1 \mu \mathrm{l}$ of each of the TBEV (TBEE-P4) and the Mengo virus (Mengo-P1) probes (see Additional file 2). Cycling conditions were as follows: reverse transcription at $50^{\circ} \mathrm{C}$ for $15 \mathrm{~min}$, an initial PCR activation step at $95^{\circ} \mathrm{C}$ for $15 \mathrm{~min}$, and 45 cycles of $95^{\circ} \mathrm{C}$ for $15 \mathrm{sec}$ and $60^{\circ} \mathrm{C}$ for $1 \mathrm{~min}$. A Corbett research Rotor-Gene RG-3000 (Switzerland) was used for amplification.

\section{Statistical analysis}

Screening pools of ticks is a time-efficient and commonly used method to determine TBEV prevalence in ticks [15,33,34,37-41]. One disadvantage of this approach is the loss of information; it is no longer possible to determine whether a positive pool contained one or more infected ticks. The minimum infection rate assumes that a positive pool contains a single infected tick [42]. All MIR estimates will be reported as percentages in the results. The numbers of ticks collected were quite low at some sites and we therefore performed power analyses to determine the probability of detecting a prevalence of TBEV greater than $1.0 \%$.

\section{Genetic analysis of TBEV sequences}

We used genetic analysis to compare our TBEV sequences from Canton Valais to other TBEV sequences from Switzerland. We partially sequenced each of two genes of TBEV: the NS5 gene and the $E$ gene. The NS5 gene codes for a highly conserved, non-structural protein with methyltransferase and RNA-dependent RNA polymerase activities [43]. The $E$ gene codes for a protein that mediates the binding of the virus to the host cells and subsequent membrane fusion $[43,44]$. Numerous studies have used the NS5 gene [32,45-47] and the E gene $[2,46,48-51]$ to study the genetics and evolution of TBEV in Europe and Switzerland [34,52]. We therefore analyzed our partial sequences of the NS5 and E genes to facilitate comparison between our TBEV sequences from Canton Valais and the rest of Switzerland and Europe.

\section{Sequencing protocols}

All TBEV-positive samples in the RT-qPCR were sequenced with respect to part of the NS5 gene (212 bp) and part of the $E$ gene (752 bp) using the primers designed by Puchhammer-Stöckl et al. (1995) [53] and Gäumann et al. (2011) [52]. The NS5 gene sequences for the 2010 and 2011 samples were obtained using an in-house sequencing protocol. The NS5 gene amplicons for the 2013 samples and the $E$ gene amplicons for all the samples (2010, 2011, and 2013) were sequenced by Microsynth. All chromatographs were checked for the accuracy of the base calls and the overall quality of the peak shape using the 4peaks software package (version 1.7.2).

\section{Phylogenetic analysis}

Phylogenetic analysis included a total of 80 nucleotide sequences: 24 sequences from the present study and 56 reference sequences from the NCBI GenBank database (see Additional file 3). The Omsk hemorrhagic fever virus [Genbank assession number AY323489], a closely related flavivirus, was chosen as the outgroup. The sequences of eight European isolates, three Siberian isolates, and three Far Eastern isolates were used to confirm the European subtype classification of the isolates found in Canton Valais. The genetic analyses of the NS5 gene and the $E$ gene contained 17 and 24 additional gene sequences, respectively (see Additional file 3 ).

DNA sequences were aligned using the default settings in Clustal Omega [54]. The alignments were concatenated and absent sequences were replaced by missing data. We used the Genetic Algorithm for Rapid Likelihood Inference (GARLI version 2.0) software package [55] for phylogenetic analysis. Phylogenetic trees were generated by a stochastic algorithm, which uses maximum likelihood (ML) to simultaneously search for the best tree topology, branch lengths, and nucleotide substitution 
model parameters. We used a nucleotide substitution model based on a general time reversible model [56], where variation in the nucleotide substitution rate follows the gamma distribution $(\Gamma)$ [57] and a proportion of invariable sites (I). Support for the topology was obtained after 1,000 non-parametric bootstrap replicates with GARLI. The bootstrap trees were summarized into one consensus tree using Dendropy v3.10.1 [58]. Our approach of using missing data is consistent with ML methods where phylogenetic accuracy can be improved with incomplete data [59].

To evaluate patterns of selection on the partial sequences of the NS5 gene and the $E$ gene, we estimated the difference $(\omega=\mathrm{dN}-\mathrm{dS})$ between the non-synonymous $(\mathrm{dN})$ and synonymous [60] substitution rates per codon site, using the single likelihood ancestor counting (SLAC) algorithm with HyPhy v2.11 [61]. Values of $\omega$ greater than zero suggest directional selection while values below zero suggest purifying selection. We used an ANOVA to test whether there were significant differences in the pattern of selection among the different functional regions of the $E$ gene.

\section{D Structural analysis of the envelope protein}

We used 3D structural analysis to study the shape of the Envelope (E) protein of TBEV. A previous study on the E protein of TBEV had determined the X-ray crystal structure of the $\mathrm{N}$-terminal ectodomain (residues 1-395) [62]. In the present study, all the substitutions were located in the C-terminal part (see Results) for which no atomic level data is available. We therefore used the known 3D structure of the $E$ protein of the dengue virus (Protein data Bank accession code 3 J27) to model the E protein of TBEV. The amino acid similarity among the flavivirus envelope proteins is $40 \%$ [63,64], which ensures that the homology model is accurate [65]. We used the HHPRED software program [66] from the MPI Bioinformatics Toolkit web service [67] to align amino acid sequences and to predict the three-dimensional structure of the full-length TBEV envelope protein. We validated our approach by confirming that the $395 \mathrm{~N}$-terminal residues of our homology model gave a good match to the known structure of the TBEV ectodomain (PDB 1SVB).

\section{Results}

\section{Ticks}

Over the four years of the study, a total of 19,331 I. ricinus ticks were collected in Canton Valais: 11,142 nymphs (57.64\%), 7,976 adults (41.26\%) and 213 larvae (1.10\%; Additional file 4). Of the 45 sites, six were found positive for TBEV including the two sites, Raron and Salgesch, which had been previously identified as TBEV foci in 2009 by Gäumann et al. (2010) [33]. All positive sites were located in a $33 \mathrm{~km}$ long transect along the Rhône River
(Figure 1). In addition to the 19,331 I. ricinus ticks, we sampled 99 Haemaphysalis punctata and 66 Dermacentor marginatus ticks but none of these ticks tested positive for TBEV.

In 2010, 6,507 I. ricinus were collected from 20 sites: 3,199 adults (49.16\%), 3,306 nymphs (50.81\%), and 2 larvae $(0.03 \%)$. The presence of TBEV in ticks was confirmed that year at both Raron ( $\mathrm{n}=1,749$ ticks) and Salgesch $(\mathrm{n}=489$ ticks). The minimum infection rate [42] was $0.74 \%$ (95\% confidence limits $(C L)=0.39-1.27 \%$ ) at Raron and $0.20 \%(95 \% \mathrm{CL}=0.01-1.13 \%)$ at Salgesch (Table 1). The remaining 4,269 ticks collected at the other 18 sites in Valais were all negative for TBEV.

In 2011, 6,804 ticks were collected from 19 sites: 2,262 adults (33.25\%), 4,535 nymphs (66.65\%), and 7 larvae $(0.10 \%)$. The tick populations at Raron and Salgesch remained infected with the virus. The MIR was $0.71 \%(95 \% \mathrm{CL}=0.08-2.56 \%)$ at Raron and $0.23 \%$ (95\% CL $=0.05-0.66 \%)$ at Salgesch. TBEV-infected ticks were detected at two additional sites this year: Rittergut-Visp (MIR $=2.41 \%$; $95 \% \mathrm{CL}=0.29-8.44 \%$ ) and Lufu-Niedergesteln (MIR $=1.92 \% ; 95 \% \mathrm{CL}=0.23-6.78 \%$; Table 1).

In 2012, 2,813 ticks were collected from eight sites. None of the ticks tested positive for TBEV including the ticks from the Raron ( $\mathrm{n}=718$ ticks) and Salgesch ( $\mathrm{n}=467$ ticks) sites. Under the assumption that the minimum infection rate was at least $1 \%$, the 2012 sampling effort at both sites had a power of more than $99 \%$ to detect at least one TBEV-infected tick (see Additional file 4).

In 2013, 3,207 ticks were collected from nine sites: 1,035 adults (32.27\%), 1974 nymphs (61.55\%), and 198 larvae (6.17\%). The MIR was $0.20 \%(95 \% \mathrm{CL}=0.01-$ $1.11 \%$ ) in Raron and $0.30 \%$ (95\% CL $=0.04-1.09 \%$ ) in Salgesch. TBEV was detected for the first time in ticks collected at Brig and Pletschen-Susten (Table 1) with a MIR of $0.16 \%(C L=0.01-0.91 \%)$ and $11.11 \%(C L=0.28-$ $48.25 \%)$, respectively.

Of the 28 pools of ticks that tested positive for TBEV between 2010 and 2013, 19 contained adults, 5 contained nymphs and 4 contained a mix of adults and nymphs (Table 1). After summing all the ticks across the TBEV-positive sites, the MIR of adult ticks (0.73\%; 95\% $\mathrm{CL}=0.44-1.13 \%)$ was 4.6 times higher than that of the nymphal ticks $(0.16 \% ; 95 \% \mathrm{CL}=0.05-0.36 \%)$ and this difference was statistically significant $\left(X^{2}=9.96, \mathrm{df}=1\right.$, $\mathrm{p}<0.002$; Table 1).

\section{Genetic analysis}

Of the 28 pools of ticks that tested positive for TBEV, 25 pools were successfully sequenced for part of the NS5 gene and 21 pools were successfully sequenced for the terminal part of the $E$ gene. A total of 46 sequences 


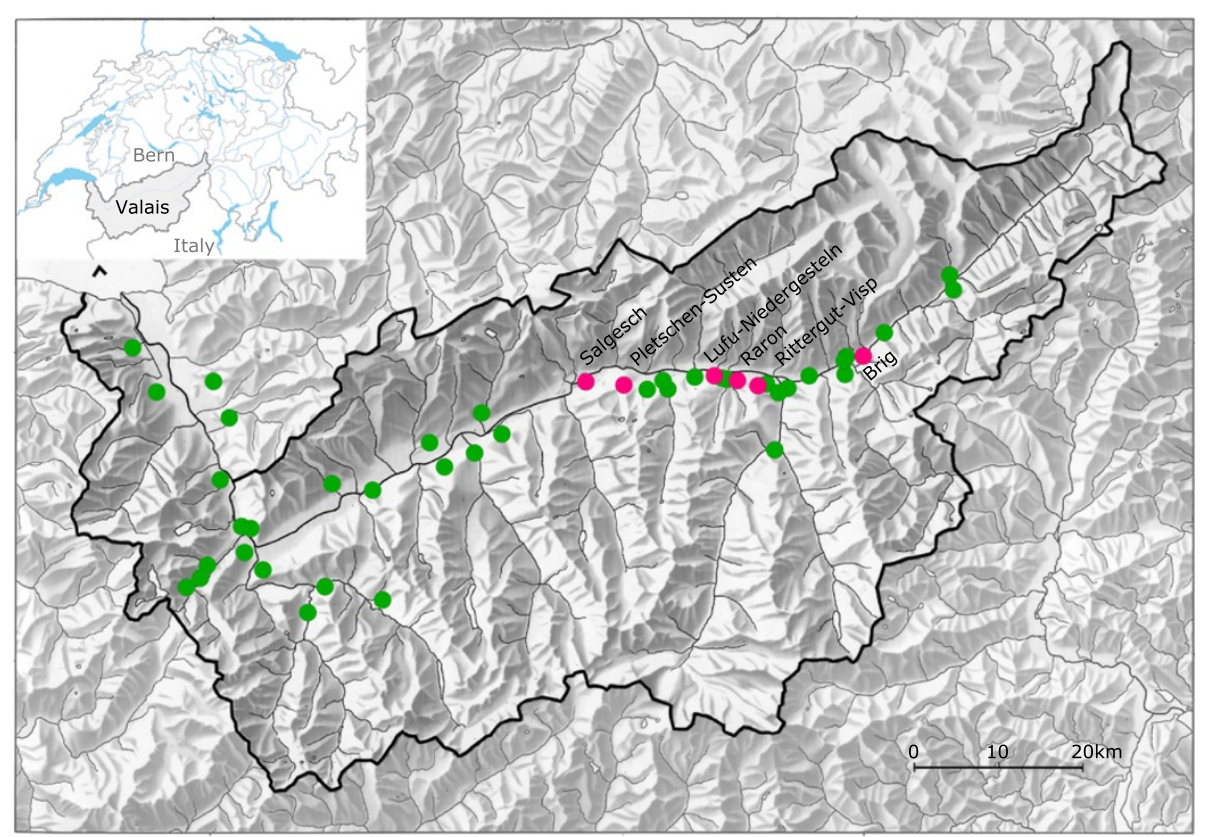

Figure 1 Map of the $\mathbf{4 5}$ sites in Canton Valais, Switzerland sampled for Ixodes ricinus ticks. The six sites where tick populations tested positive for TBEV are named and shown in red. The 39 sites where tick populations tested negative for TBEV are shown in green. The map was made using the QGIS 1.8.0 Lisboa software.

were submitted to the NCBI GenBank database (see Additional file 5 for accession numbers).

The 25 partial DNA sequences of the NS5 gene included two different variants. One variant contained 24 DNA sequences from five different sites (Raron, Salgesch, Niedergesteln, Susten, Visp), whereas the other variant, which had 5 nucleotide substitutions, consisted of a single sequence from the 2013 Brig site. DNA sequence variability in the NS5 gene was therefore low $(2.35 \%=5$ variable nucleotides $/ 212$ total nucleotides $)$. One of the five nucleotide substitutions $(20.0 \%)$ was non-synonymous and occurred at position number 302 in the NS5 gene.

The 21 partial DNA sequences of the $E$ gene included seven different variants. The Raron site had three $E$ gene variants whereas all other sites had a single variant. The $E$ gene variant in Salgesch was the same as the variant in Lufu-Pletschen. The terminal part of the $E$ gene had 29 nucleotide substitutions and the DNA sequence variability was low $(3.85 \%=29$ variable nucleotides $/ 752$ total nucleotides). Six of the 29 substitutions (20.7\%) were non-synonymous and all these mutations were assembled on a 94 bp fragment of the $E$ gene (Figure 2). Twenty of the 29 nucleotide substitutions were only found in the Brig isolate suggesting that this variant was quite different from the other variants collected in Valais.

Comparison of the synonymous [60] and non-synonymous $(\mathrm{dN})$ substitution rates found that $\mathrm{dS}>\mathrm{dN}$ at all amino acid positions in the partial sequences of both the
NS5 gene and the $E$ gene (data not shown). This result suggests that both the NS5 gene and the $E$ gene are under purifying selection. For the subset of the 60 Swiss TBEV isolates, the ANOVA found no significant differences in the pattern of selection among the five domains of the Envelope protein $\left(\mathrm{F}_{4,243}=0.82, \mathrm{p}=0.514\right)$.

\section{Phylogenetic analysis}

In this study, all TBEV isolates from Canton Valais belonged to the European subtype. The DNA sequences of the seven strains from Canton Valais were 98.24 to $97.00 \%$ similar to the reference strain of the European subtype (Neudoerlf; Genbank $=$ U27495). In contrast, the similarity with the reference strains of the Far Eastern (Sofjin; Genbank = AB062064) and the Siberian (Vasilenko; Genbank = AF069066) subtypes ranged between $83.50 \%$ and $87.81 \%$. All isolates from Canton Valais were closely related to each other, except the isolate from Brig $(\mathrm{C} 20 \mathrm{~m})$, and they were closely related to other Swiss TBEV isolates obtained from previous studies [32,34,52] (Figure 3).

\section{D Structural analysis}

The 3D structure of the full-length Envelope (E) protein of TBEV is currently unknown. We therefore used the $\mathrm{E}$ protein of the dengue virus [68] to create a homology model of the E protein of TBEV (Figure 4). The flavivirus $\mathrm{E}$ protein ( 495 amino acids) consists of a large $\mathrm{N}$-terminal ectodomain ( 395 amino acids) [62] and a 
Table 1 The minimum infection rate [42] of Ixodes ricinus ticks at the TBEV foci

\begin{tabular}{|c|c|c|c|c|c|c|c|c|c|c|c|c|c|c|c|c|}
\hline \multirow[b]{2}{*}{ Site } & \multirow[b]{2}{*}{ Year } & \multicolumn{3}{|c|}{ Number of ticks sampled } & \multicolumn{3}{|c|}{ Positive pools/total pools } & \multicolumn{3}{|c|}{ Adults } & \multicolumn{3}{|c|}{ Nymphs } & \multicolumn{3}{|c|}{ Mix } \\
\hline & & Adult & Nymph & Larva & Adult & Nymph & $\operatorname{Mix}^{\mathrm{a}}$ & MIR & LL & UL & MIR & LL & UL & MIR & LL & UL \\
\hline Raron & 2010 & 875 & 872 & 2 & $11 / 135$ & $0 / 45$ & $2 / 21$ & 1.26 & 0.63 & 2.24 & 0.00 & 0.00 & 0.42 & 0.74 & 0.39 & 1.27 \\
\hline Salgesch & 2010 & 271 & 218 & 0 & $0 / 11$ & $1 / 6$ & $0 / 0$ & 0.00 & 0.00 & 1.35 & 0.46 & 0.01 & 2.53 & 0.20 & 0.01 & 1.13 \\
\hline Lufu-Niedergesteln & 2011 & 38 & 66 & 0 & $1 / 2$ & $1 / 2$ & $0 / 0$ & 2.63 & 0.07 & 13.81 & 1.52 & 0.04 & 8.16 & 1.92 & 0.23 & 6.78 \\
\hline Raron & 2011 & 156 & 124 & 0 & $2 / 30$ & $0 / 8$ & $0 / 0$ & 1.28 & 0.15 & 4.55 & 0.00 & 0.00 & 2.93 & 0.71 & 0.08 & 2.56 \\
\hline Rittergut-Visp & 2011 & 73 & 10 & 0 & $2 / 6$ & $0 / 1$ & $0 / 0$ & 2.74 & 0.33 & 9.55 & 0.00 & 0.00 & 30.85 & 2.41 & 0.29 & 8.44 \\
\hline Salgesch & 2011 & 320 & 1012 & 0 & $1 / 38$ & $2 / 23$ & $0 / 0$ & 0.31 & 0.01 & 1.73 & 0.2 & 0.02 & 0.72 & 0.23 & 0.05 & 0.66 \\
\hline Brig & 2013 & 397 & 213 & 1 & $1 / 19$ & $0 / 4$ & $0 / 1$ & 0.25 & 0.01 & 1.40 & 0.00 & 0.00 & 1.72 & 0.16 & 0.01 & 0.91 \\
\hline Pletschen_Susten & 2013 & 7 & 2 & 0 & $0 / 0$ & $0 / 0$ & $1 / 1$ & 0.00 & 0.00 & 40.96 & 0.00 & 0.00 & 84.19 & 11.11 & 0.28 & 48.25 \\
\hline Raron & 2013 & 261 & 239 & 0 & $0 / 14$ & $0 / 6$ & $1 / 1$ & 0.00 & 0.00 & 1.40 & 0.00 & 0.00 & 1.53 & 0.20 & 0.01 & 1.11 \\
\hline Salgesch & 2013 & 222 & 434 & 6 & $1 / 14$ & $1 / 9$ & $0 / 1$ & 0.45 & 0.01 & 2.49 & 0.23 & 0.01 & 1.28 & 0.30 & 0.04 & 1.09 \\
\hline Total & & 2620 & 3190 & 9 & $19 / 269$ & $5 / 104$ & $4 / 25$ & 0.73 & 0.44 & 1.13 & 0.16 & 0.05 & 0.36 & 0.48 & 0.32 & 0.7 \\
\hline
\end{tabular}

$\mathrm{LL}=$ lower $95 \%$ confidence limit.

$\mathrm{UL}=$ upper $95 \%$ confidence limit.
amixture of adults, nymphs and larvea.

'mixture of adults, nymphs and larvea.
For each of the ten combinations of site and year, the tick sample sizes are shown for each stage (adult, nymph, larva). The proportion of TBEV-positive pools is shown for pools of three different stage compositions: adults, nymphs, and mixture (adults, nymphs, larvae). The MIR is shown separately for adults, nymphs, and mixture (adults, nymphs, larvae). The MIR and the $95 \%$ confidence limits are expressed as a percent. 
C-terminal trans-membrane region (anchor) connected by the stem region (Figure 4A). This stem region (colored magenta in Figure 4) consists of three helices ( $\mathrm{H} 1, \mathrm{H} 2$, and $\mathrm{H} 3$ ) that lie flat on the viral membrane (Figure 4A). Our partial DNA sequences of the $E$ gene only encode a portion of the $\mathrm{E}$ protein from amino acid residues 249 to 496 (C-terminus). This portion of the $\mathrm{E}$ protein includes part of the ectodomain, the stem and the trans-membrane region. All non-synonymous substitutions in the partial $E$ gene sequences of the Canton Valais isolates mapped to the stem region. Most of the amino acid substitutions (e.g. residues 437, 440 and 444) were located in the H3 helix (Figure 4B). One amino acid substitution (residue 416) was located at the break between the $\mathrm{H} 1$ and $\mathrm{H} 2$ helices (Figure 4C).

\section{Discussion}

Tick-borne encephalitis virus (TBEV) was detected in questing Ixodes ricinus ticks in 2010, 2011 and 2013 at Raron and Salgesch in Canton Valais, confirming the temporal persistence of these two TBEV foci since their discovery in 2009 [33]. The virus was not detected in 2012 at either site but this could be explained by the smaller sample sizes of ticks collected that year $(n=718$ ticks for Raron and $n=467$ ticks for Salgesch). Our power analysis of the 2012 data showed that we had a 75\% chance of detecting TBEV-positive pools if the 2012 MIR was equal to the 2013 MIR (0.20\%). A previous field study spanning ten years in Latvia found that the prevalence of TBEV in I. ricinus ticks was characterized by high temporal variability $[69,70]$. In addition to 


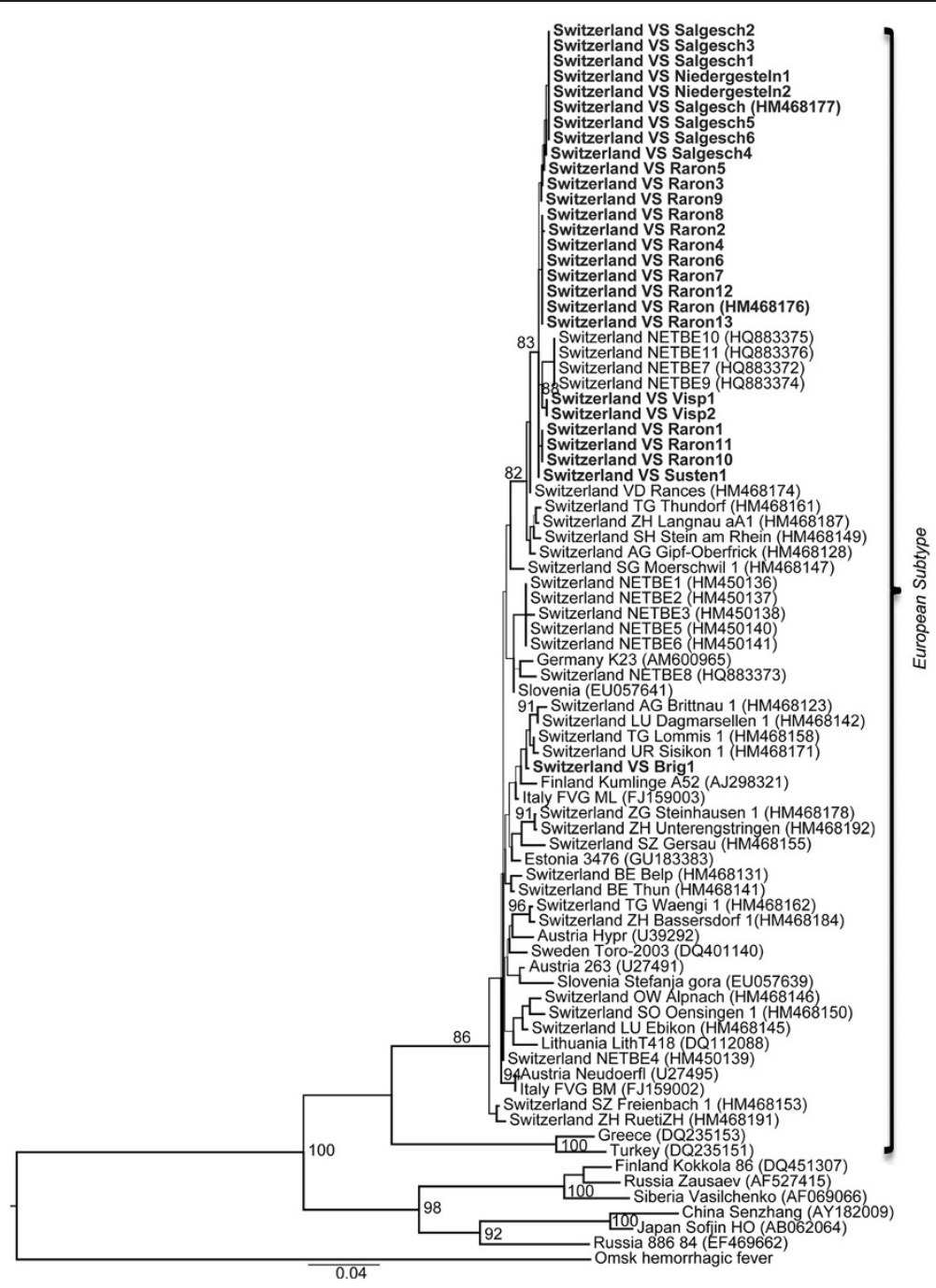

Figure 3 Phylogenetic tree of the TBEV isolates from Canton Valais. The sequences of the TBEV isolates were based on concatenation of the NS5 gene (212 bp) and the envelope gene (752 bp). The Omsk hemorrhagic fever virus was used as an out-group to root the tree. The TBEV sequences from Canton Valais are shown in bold. GenBank accession numbers are indicated and bootstrap values $\geq 80 \%$ are shown. The scale bar corresponds to 0.04 nucleotides per site.

confirming the TBEV-positive status of Raron and Salgesch, this study found four new TBEV foci. All six TBEV foci were located in a $33 \mathrm{~km}$ long transect along the Rhône River (Figure 1). Repeated detection of the virus at Raron and Salgesch and the discovery of four new TBEV foci indicate that this part of Canton Valais is a risk area for TBEV.

Altitude can play an important role in the distribution of $I$. ricinus and thus tick-borne infections. In the present study, the elevation of the six TBEV foci ranged between $570 \mathrm{~m}$ and $980 \mathrm{~m}$ above sea level and none of the eight sites above 1,000 meters tested positive for TBEV. Studies in other mountain regions have found TBEV-infected ticks or goats at higher elevations. In the Czech Republic, TBEV-infected I. ricinus populations were found up to 1,100 meters [71]. In the Austrian Alps, cases of human TBE caused by non-pasteurized goat milk have occurred at elevations above 1,500 meters [72]. In Canton Valais, stable populations of I. ricinus have been found at 1,450 meters [73]. Taken together, these studies suggest that TBEV could spread to higher elevation tick populations in the future. Epidemiological models incorporating climate change project that TBEV will be found at higher altitudes and latitudes in Europe in the coming decades [12] although these same models project that TBEV will be extirpated from most regions of Switzerland by 2020 [74].

Detection of TBEV-infected ticks at Rittergut-Visp in 2011 was linked with the first autochthonous human case of TBE described in Canton Valais [75]. In contrast, 

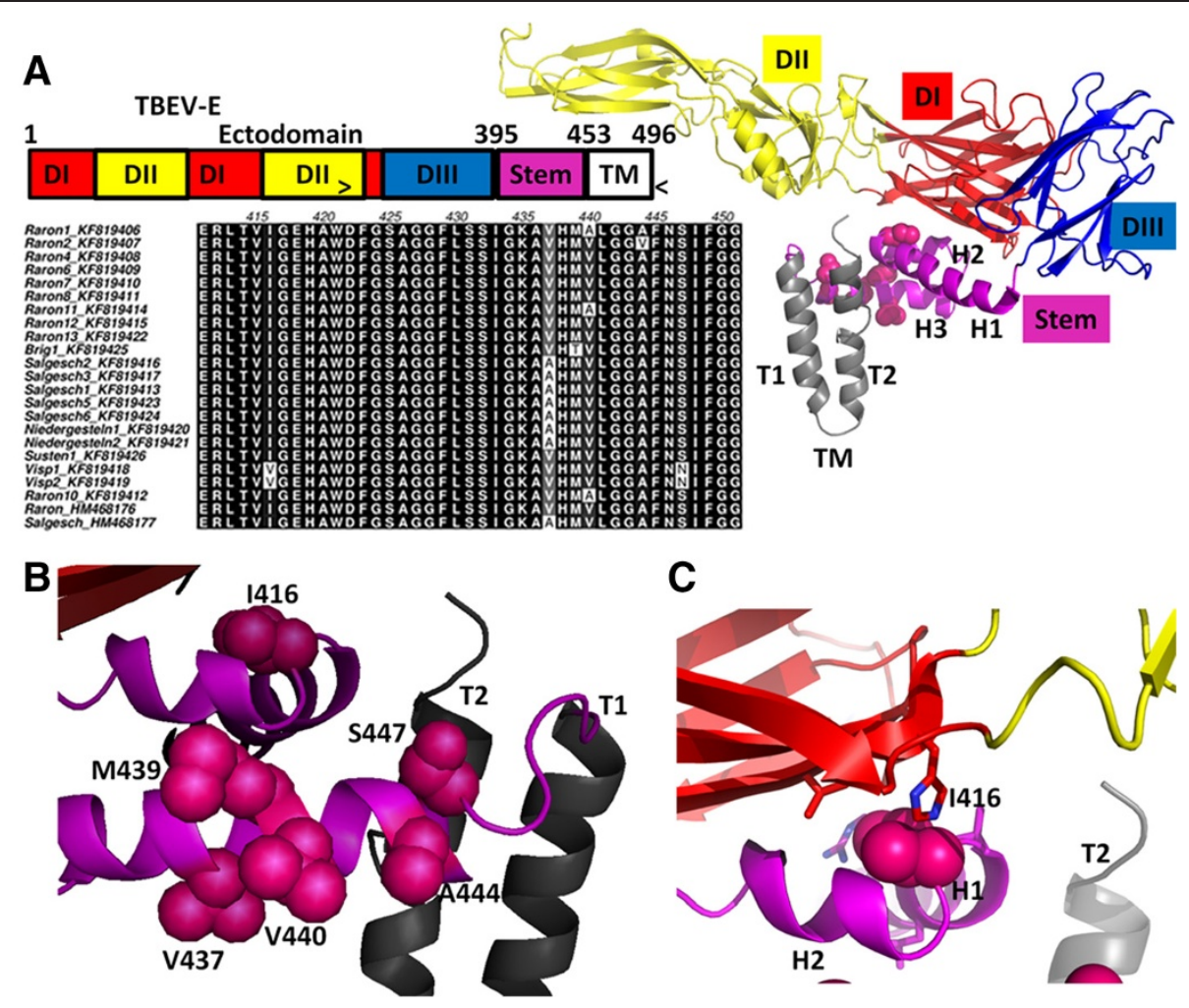

Figure 4 Locations of the mutations in the Envelope protein of TBEV are shown. (A) Left, top: the primary structure of the TBEV envelope protein and its organization into the ectodomain, stem, and trans-membrane (TM) region. The region encompassing amino acid residues $249-496$ (indicated by " $>$ " and " $<$ ") corresponds to the terminal part of the envelope gene that was sequenced in this study. All non-synonymous substitutions in the partial sequences of the Canton Valais TBEV isolates mapped to the stem region of the Envelope protein. (A) Left, bottom: Alignment of the Envelope protein amino acid sequences of the 21 Canton Valais TBEV isolates reported in this study and two reference sequences (Raron_HM468176 and Salgesch_HM468177). Amino acid substitutions were found at positions 416, 437, 439, 440, 444 and 447. Right: the three-dimensional structure of a single TBEV E molecule based on the homology model of the dengue virus E molecule (PDB 3 J27). The N-terminal ectodomain is attached to the stem and consists of three domains: central domain (D1; in red), the fusion domain (D11; in yellow), and the lateral domain (DIIl; in blue). The stem consists of three helices ( $\mathrm{H} 1, \mathrm{H} 2$, and $\mathrm{H} 3$; in magenta) and the side chains of the amino acid substitutions are shown (pink spheres). The two trans-membrane helices ( $\mathrm{T} 1$ and $\mathrm{T2}$; in gray) are inserted in the viral membrane. (B) Close-up of the variable residues in the H3 helix of the stem. The mutated residues are labeled. (C) Close-up of the mutant 1416 residue, which projects into a hydrophobic pocket (residues lining this pocket are displayed as sticks).

a tick collection site (Oberi Albe-Visp), which was only 200 meters from the exact location where the TBE patient was bitten, tested negative for TBEV in that same year. This example shows the spatio-temporal patchiness of TBEV in tick populations and also shows the difficulty of using TBEV prevalence in ticks to predict the risk of TBE for humans. Similarly, previous studies in Poland, Germany and Switzerland found that tick sampling could not assure virus detection in known endemic foci $[34,76,77]$.

Temporal persistence of TBEV-positive ticks in a given location remains the gold standard for defining TBEV foci. However, the generally low prevalence of TBEV in tick populations also means that this gold standard is time-consuming and inefficient. For this reason, numerous field studies have used serology of vertebrate hosts to identify TBEV foci [78-84]. As vertebrate hosts can feed many ticks, they effectively amplify the TBEV signal in a given area. In the present study, the TBEV foci discovered at Pletschen-Susten and Brig in 2013 were predicted from an immunological survey of sera obtained from local populations of domestic goats (Rieille, in preparation). These preliminary results confirm that using vertebrate hosts as sentinels is an efficient method of detecting new TBEV foci $[80,85,86]$.

In this study, a total of 19,331 I. ricinus ticks were collected over four consecutive years and processed in pools, of which $2.7 \%(28 / 1,033)$ tested positive for TBEV (see Additional file 4). The prevalence of TBEV in the tick populations of Canton Valais (Table 1) was similar to previous studies in Europe $[15,47,87,88]$ and Switzerland $[32-34,40,89]$. In these other studies, the prevalence of TBEV in free-living ticks ranged from 0.1 to $5.0 \%$ [9] The high prevalence found at Pletschen-Susten (11.11\%) was 
based on a small sample size ( $\mathrm{n}=9$ ticks). A few other studies have found unusually high prevalence of TBEV in ticks such as $14.3 \%$ in an endemic area of central Switzerland [90] or $14.0 \%$ and $26.6 \%$ in Slovakia and Latvia, respectively [70,91]. Across the ten TBEV-positive combinations of site and year (Table 1), the MIR of adult ticks was 4.6 times higher than that of nymphs and this difference was statistically significant. We expected adult ticks to have a higher infection prevalence than nymphal ticks because they have taken twice as many blood meals and are therefore twice as likely to have encountered the virus [8]. Other studies have found that the prevalence of TBEV is higher in nymphs than in adult ticks $[32,90]$.

Phylogenetic analyses of the partial sequences of the NS5 gene and the $E$ gene found that all TBEV strains from Canton Valais belonged to the European subtype and were closely related to other Swiss isolates (Figure 3). The isolate from Brig appeared to belong to a different lineage. The presence of two TBEV lineages in Canton Valais suggests that TBEV emerged at Brig independently from the other TBEV foci. We currently do not know when and how TBEV reached Canton Valais. Canton Valais is surrounded by high mountain ranges to the north and south $(2,000$ to 3,000 meters above sea level) that are difficult to cross for the relevant reservoir hosts (i.e. rodents). This geological isolation may explain why this Canton has remained TBEV-free for so long even though the virus is endemic in most of Switzerland. There is some evidence that birds can disperse TBEV-infected ticks during migration [92-94] and that ticks can persist when transported to new habitats by birds [95]. Cervids are another plausible dispersal host for TBEV because they are both highly mobile and frequently parasitized by ticks. A number of studies have shown that cervids such as roe deer play an important role in the epidemiology of $\mathrm{TBE}$ $[80,96]$. These animals could bring the virus into Canton Valais by following low elevation wildlife corridors. Thus both birds and cervids could have played an important role in bringing TBEV to Canton Valais.

Anthropogenic activity such as road construction [23] and landscape features such as river systems [26] may also play a role in the dispersal of TBEV. Transport tunnels that cross the surrounding mountain ranges connect Canton Valais to TBEV-endemic areas. For example, the Lötschberg Tunnel, which was opened in June 2007, is a $34.5 \mathrm{~km}$ railway tunnel that connects Raron in Canton Valais to Frutigen in Canton Bern, where TBEV is endemic. The Simplon Tunnel is a $19.8 \mathrm{~km}$ auto tunnel that connects Brig in Canton Valais to Iselle in northern Italy. A study on this tunnel demonstrated the presence of house mice (Mus domesticus), and thus another route by which TBEV could enter Canton Valais [97]. In the present study, we could not demonstrate that strains from Canton Valais were genetically more similar to strains from Canton Bern (HM468131; HM468141), strains from Italy (FJ159003; FJ159002) or strains from other geographic locations represented in our analysis. Future studies examining more sequences from surrounding areas may help clarify the origins of the TBEV strains in Canton Valais.

Genetic variability was low for both the NSS and the $E$ gene but the latter was slightly better for distinguishing variants. Comparison of the non-synonymous and synonymous substitution rates found that numerous sites in the NS5 gene and the $E$ gene were under purifying selection. These results are in agreement with other studies showing that the TBEV genome is under purifying selection $[26,51]$. However, we found no evidence that the pattern of selection varied among the different domains of the Envelope protein.

The Envelope protein of TBEV is composed of two regions: the so-called ectodomain and the stem-anchor region [98]. Our partial DNA sequences of the $E$ gene only covered the part of the E protein that includes part of the ectodomain, and the stem-anchor region. Our homology model of these partial sequences suggested that all non-synonymous substitutions of the Canton Valais isolates were located in the stem region of the $\mathrm{E}$ protein (Figure 4). The stem region plays an important role during the fusion process whereby the virus enters the target cells of the host $[64,98]$. However, the functional role (if any) of these amino acid substitutions in the stem region of the $\mathrm{E}$ protein of TBEV remains unknown.

In Switzerland, the Federal Office of Public Health $(\mathrm{FOPH})$ requires physicians and diagnostic laboratories to report all human cases of TBE. This mandatory reporting practice has been in effect in Switzerland since 1989 [99]. Over the last 11 years (2002 to 2013), the human caseload of TBE in Canton Valais $(n=14$ cases) represents a tiny fraction $(0.84 \%)$ of the total caseload in Switzerland ( $\mathrm{n}=1,668$ cases). The human risk of TBE in Canton Valais is therefore low compared to other areas in Switzerland. However, the annual human caseload of TBE in Canton Valais has increased from 0.0 to 1.28 cases per 100,000 inhabitants over the last ten years (2002 to 2012), and over 78\% (11/14) of the cases have occurred in the 5 last years. These observations suggest that $\mathrm{TBE}$ is a rising public health problem in Canton Valais. A similar increase in TBE has been observed in another alpine area in Central Europe, the state of Tyrol in Austria [100].

\section{Conclusions}

In conclusion, this study confirms the presence of TBEV in $I$. ricinus tick populations in the southern part of Switzerland. In Canton Valais, the risk of TBEV appears to be highest along a $33 \mathrm{~km}$ stretch of the Rhône River 
between Salgesch and Brig. While the human caseload of TBE is low in Canton Valais it appears to be increasing. To limit the number of TBEV-infected patients in the future, we recommend educating the Valaisian population about the prevention of tick bites and the availability of the TBEV vaccine. Other methods of TBEV detection and surveillance should be used including seroepidemiological surveys of sentinel vertebrate hosts such as wild rodents or livestock.

\section{Additional files}

Additional file 1: The $\mathbf{4 5}$ sites in Canton Valais, Switzerland that were sampled for Ixodes ricinus ticks. For each site, the site name, year of sampling, altitude, and the GPS coordinates are shown.

Additional file 2: Primers and probes used in the QPCR to detect TBEV in Ixodes ricinus ticks. The TBEV detection primers amplified an $87 \mathrm{bp}$ segment of the envelope gene. The primers for the Mengo virus amplified a 103 bp segment of the $5^{\prime}$ non-coding region and were used as an internal control to confirm that each RT-qPCR reaction worked.

Additional file 3: The 55 TBEV sequences used in the phylogenetic analysis. Shown are the TBEV subtype classification (Far-Eastern, Siberian, or European), the isolate name, the location where the isolate was obtained, and the Genbank accession number.

Additional file 4: Probability to detect at least one TBEV-positive tick for each combination of site and year. The probability to detect at least one TBEV-positive tick ( $P_{\text {detect }}$ ) depends on the sampling effort for each combination of site and year. The sampling effort was based on the number of adults, nymphs, and larvae that were collected for each combination of site and year. The power analysis assumed that $>1 \%$ of the ticks were infected with the tick-borne encephalitis virus.

Additional file 5: The PubMed accession number of the partial sequences of the NS5 gene and the envelope gene are shown. These sequences came from the 28 pools of Ixodes ricinus ticks that tested positive for tick-borne encephalitis virus. These ticks had been collected from different sites in Canton Valais between 2010-2013. Pool content refers to whether the pools contained adult ticks, nymphal ticks, or a mixture. Also shown are the numbers of cycles at which the sample tested positive for each of the three replicate runs of the GPCR assay.

\section{Competing interests}

The authors declare that they have no competing interests.

\section{Authors' contributions}

NR carried out the fieldwork, laboratory work, and data analysis. SA helped develop the in-house sequencing protocol. SB did the 3D structural analysis of the TBEV Envelope protein. CF did the phylogenetic analysis. NR, OP, LG and MJV participated in the design of the study. NR and MJV wrote the manuscript. All authors helped edit the final manuscript. All authors read and approved the final manuscript.

\section{Acknowledgements}

We thank Dr C. Beuret from the Spiez Laboratory (Federal Office for Civil Protection, Switzerland) for providing the Mengo virus and instructions for the tick RNA extraction protocol. We thank Dr C. Burri and Dr E. Lommano (Institute of Biology, University of Neuchâtel) for help with the statistical analysis. We are grateful to G. Litsios (University of Lausanne, Lausanne, Switzerland) for help with the phylogenetic analyses. Many thanks to the research foundation of ICHV (Institut Central des Hôpitaux Valaisans), the public health service of Canton Valais, and especially Dr N. Troillet, Dr G. Dupuis and $\operatorname{Dr}$ C. Ambord for financial support. This work is part of the PhD thesis of Nadia Rieille.

\section{Author details}

${ }^{1}$ Central Institute of Valais Hospitals, Infectious diseases, Av Grand Champsec 86, Sion, Switzerland. 'Laboratory of Ecology and Evolution of Parasites, Institute of Biology, University of Neuchâtel, Rue Emile-Argand 11, 2000 Neuchâtel, Switzerland. ${ }^{3}$ Laboratoire de Virologie Moléculaire et Structurale, CNRS UPR3296, 1 avenue de la Terrasse, 91198 Gif-sur-Yvette cedex, France. ${ }^{4}$ Inter-institutional Grad Program on Bioinformatics, University of Sao Paulo, Matao Street 1010, Sao Paulo, Brazil. ${ }^{5}$ Central Institute of Valais Hospitals, Genetics, Av Grand Champsec 86, Sion, Switzerland. ${ }^{6}$ Laboratory of Eco-Epidemiology of Parasites, Institute of Biology, University of Neuchâtel, Rue Emile-Argand 11, 2000 Neuchâtel, Switzerland.

Received: 6 May 2014 Accepted: 13 September 2014

Published: 22 September 2014

\section{References}

1. Kunze U, ISW TBE: Tick-borne encephalitis: new paradigms in a changing vaccination environment. Wien Med Wochenschr 2011, 161:361-364.

2. Ecker M, Allison SL, Meixner T, Heinz FX: Sequence analysis and genetic classification of tick-borne encephalitis viruses from Europe and Asia. J Gen Virol 1999, 80:179-185.

3. Fauquet CM, Mayo MA, Maniloff J, Desselberger U, Ball LA: Flaviviridae in Virus taxonomy, eigth report of international committee on taxonomy of viruses. Elsevier, academic press; 2005.

4. Mansfield KL, Johnson N, Phipps LP, Stephenson JR, Fooks AR, Solomon T: Tick-borne encephalitis virus - a review of an emerging zoonosis. $J$ Gen Virol 2009, 90:1781-1794.

5. Labuda M, Nuttall PA, Kozuch O, Eleckova E, Williams T, Zuffova E, Sabo A: Non-viraemic transmission of tick-borne encephalitis virus: a mechanism for arbovirus survival in nature. Experientia 1993, 49:802-805.

6. Rehacek J: Transovarial transmission of tick-borne encephalitis virus by ticks. Acta Virol 1962, 6:220-226.

7. Danielova V, Holubova J: Transovarial transmission rate of tick borne encephalitis virus in Ixodes ricinus ticks. In Modern Acarology. Edited by Dusbabeck F, Bukva V. The Hague, Nederlands: SPB Academic; 1991.

8. Gritsun TS, Lashkevich VA, Gould EA: Tick-borne encephalitis. Antiviral Res 2003, 57:129-146.

9. Süss J: Tick-borne encephalitis 2010: epidemiology, risk areas, and virus strains in Europe and Asia-an overview. Ticks Tick Borne Dis 2011, 2:2-15.

10. Korenberg El: Comparative ecology and epidemiology of lyme disease and tick-borne encephalitis in the former Soviet Union. Parasitol Today 1994, 10:157-160.

11. Pavlovsky E: In Natural nidality of transmissible diseases in relation to landscape epidemiology of zooanthroponoses. In Book The Challenge of Epidemiology, Issues and Selected Readings. Edited by Buck C, Llopis A, Najera E, Terris M. Washington, US: Pan American Health Organization; 1988.

12. Randolph SE: The shifting landscape of tick-borne zoonoses: tick-borne encephalitis and Lyme borreliosis in Europe. Philos Trans R Soc Lond B Biol Sci 2001, 356:1045-1056.

13. Dumpis U, Crook D, Oksi J: Tick-borne encephalitis. Clin Infect Dis 1999, 28:882-890

14. Lindquist L Vapalahti O: Tick-borne encephalitis. Lancet 2008, 371:1861-1871.

15. Skarpaas T, Golovljova I, Vene S, Ljostad U, Sjursen H, Plyusnin A, Lundkvist A: Tickborne encephalitis virus, Norway and Denmark. Emerg Infect Dis 2006, 12:1136-1138.

16. Csango PA, Blakstad E, Kirtz GC, Pedersen JE, Czettel B: Tick-borne encephalitis in southern Norway. Emerg Infect Dis 2004, 10:533-534.

17. Jääskelainen $\mathrm{AE}$, Tonteri $\mathrm{E}$, Sironen $\mathrm{T}$, Pakarinen $\mathrm{L}$, Vaheri A, Vapalahti O: European subtype tick-borne encephalitis virus in Ixodes persulcatus ticks. Emerg Infect Dis 2011, 17:323-325.

18. Fomsgaard A, Christiansen CB, Bodker R: First identification of tick-borne encephalitis in Denmark outside of Bornholm, August 2009. Euro Surveill 2009, 14:2-3.

19. Herpe B, Schuffenecker I, Pillot J, Malvy D, Clouzeau B, Bui N, Vargas F, Gruson D, Zeller H, Lafon ME, Fleury H, Hilbert G: Tickborne encephalitis, southwestern France. Emerg Infect Dis 2007, 13:1114-1116.

20. Randolph SE, on behalf of the EDEN-TBD sub-project team: Human activities predominate in determining changing incidence of tick-borne encephalitis in Europe. Euro Surveill 2010, 15:24-31. 
21. Gray JS, Dautel H, Estrada-Pena A, Kahl O, Lindgren E: Effects of climate change on ticks and tick-borne diseases in Europe. Interdiscip Perspect Infect Dis 2009, 2009:593232.

22. Zanotto PM, Gao GF, Gritsun T, Marin MS, Jiang WR, Venugopal K, Reid HW, Gould EA: An arbovirus cline across the northern hemisphere. Virology 1995, 210:152-159.

23. Kovalev SY, Chernykh DN, Kokorev VS, Snitkovskaya TE, Romanenko W: Origin and distribution of tick-borne encephalitis virus strains of the Siberian subtype in the Middle Urals, the north-west of Russia and the Baltic countries. J Gen Virol 2009, 90:2884-2892.

24. Weidmann M, Ruzek D, Krivanec K, Zoller G, Essbauer S, Pfeffer M, Zanotto PM, Hufert FT, Dobler G: Relation of genetic phylogeny and geographical distance of tick-borne encephalitis virus in Central Europe. J Gen Virol 2011, 92:1906-1916.

25. Heinze DM, Gould EA, Forrester NL: Revisiting the clinal concept of evolution and dispersal for the tick-borne flaviviruses by using phylogenetic and biogeographic analyses. J Virol 2012, 86:8663-8671.

26. Weidmann M, Frey S, Freire CC, Essbauer S, Ruzek D, Klempa B, Zubrikova D, Vogerl M, Pfeffer M, Hufert FT, Zanotto PM, Dobler G: Molecular phylogeography of tick-borne encephalitis virus in central Europe. J Gen Virol 2013, 94:2129-2139.

27. Krech $U$, Jung F, Jung M: Central European tick-borne encephalitis in Switzerland. Schweiz Med Wochenschr 1969, 99:282-285.

28. Spiess H, Mumenthaler M, Burkhardt S, Keller H: Central European encephalitis ("tick-borne encephalitis") in Switzerland. Schweiz Med Wochenschr 1969, 99:277-282.

29. Radda A, Schmidtke W, Wandeler A: Isolation of tick-borne encephalitis (TBE) virus from Ixodes ricinus collected in the Kantom Zurich. Switzerland Zentralbl Bakteriol Orig A 1974, 229:268-272.

30. Wyler R, Schmidtke W, Kunz C, Radda A, Henn V, Meyer R: Tick-borne encephalitis in the Schaffhausen region: isolation of virus from ticks and serological studies. Schweiz Med Wochenschr 1973, 103:1487-1492.

31. De Marval F: Etude séroépidemiologique de l'encéphalite à tiques et de la borréliose de Lyme en Suisse. Biology: Neuchâtel; 1994.

32. Burri C, Bastic V, Maeder G, Patalas E, Gern L: Microclimate and the zoonotic cycle of tick-borne encephalitis virus in Switzerland. J Med Entomol 2011, 48:615-627.

33. Gäumann R, Muhlemann K, Strasser M, Beuret CM: High-throughput procedure for tick surveys of tick-borne encephalitis virus and its application in a national surveillance study in Switzerland. App/ Environ Microbiol 2010, 76:4241-4249

34. Lommano E, Burri C, Maeder G, Guerne M, Bastic V, Patalas E, Gern L: Prevalence and genotyping of tick-borne encephalitis virus in questing Ixodes ricinus ticks in a new endemic area in western Switzerland. J Med Entomol 2012, 49:156-164.

35. De Valliere S, Cometta A, Zimmermann H, Vaudaux B, Meylan P: Evidence of new foci of tick-borne encephalitis in the French speaking part of Switzerland. Rev Med Suisse 2006, 2:2189. 2191-2184.

36. Cotty A: Clé de détermination des Ixodidae et Amblyommidae de Suisse. Neuchâtel, Suisse: Université de Neuchâtel; 1985.

37. Han X, Aho M, Vene S, Peltomaa M, Vaheri A, Vapalahti O: Prevalence of tick-borne encephalitis virus in Ixodes ricinus ticks in Finland. J Med Virol 2001, 64:21-28.

38. Jääskelainen AE, Tikkakoski T, Uzcategui NY, Alekseev AN, Vaheri A, Vapalahti O: Siberian subtype tickborne encephalitis virus, Finland. Emerg Infect Dis 2006, 12:1568-1571.

39. Juceviciene $A$, Zygutiene $M$, Leinikki P, Brummer-Korvenkontio $H$, Salminen M, Han X, Vapalahti O: Tick-borne encephalitis virus infections in Lithuanian domestic animals and ticks. Scand J Infect Dis 2005, 37:742-746

40. Wicki R, Sauter P, Mettler C, Natsch A, Enzler T, Pusterla N, Kuhnert $P$, Egli G, Bernasconi M, Lienhard R, Lutz H, Leutenegger CM: Swiss Army Survey in Switzerland to determine the prevalence of Francisella tularensis, members of the Ehrlichia phagocytophila genogroup, Borrelia burgdorferi sensu lato, and tick-borne encephalitis virus in ticks. Eur J Clin Microbiol Infect Dis 2000, 19:427-432

41. Danielova V, Holubova J, Pejcoch M, Daniel M: Potential significance of transovarial transmission in the circulation of tick-borne encephalitis virus. Folia Parasitol (Praha) 2002, 49:323-325.
42. Kunze $U$, Asokliene L, Bektimirov T, Busse A, Chmelik V, Heinz FX, Hingst V, Kadar F, Kaiser R, Kimmig P, Kraigher A, Krech T, Linquist L, Lucenko I, Rosenfeldt V, Ruscio M, Sandell B, Salzer H, Strle F, Süss J, Zilmer K, Mutz I: Tick-borne encephalitis in childhood-consensus 2004. Wien Med Wochenschr 2004, 154:242-245

43. Chambers TJ, Hahn CS, Galler R, Rice CM: Flavivirus genome organization, expression and replication. Annu Rev Microbiol 1990, 44:649-688.

44. Knipe DM, Howley PM: Flaviviridae: The Viruses and their Replication in Fields Virology. 5th edition. Philadelphia: Eds. Lippincott-Raven Publishers; 2007.

45. Fajs L, Durmisi E, Knap N, Strle F, Avsic-Zupanc T: Phylogeographic characterization of tick-borne encephalitis virus from patients, rodents and ticks in Slovenia. PLoS One 2012, 7:e48420.

46. Grard G, Moureau G, Charrel RN, Lemasson JJ, Gonzalez JP, Gallian P, Gritsun TS, Holmes EC, Gould EA, de Lamballerie X: Genetic characterization of tick-borne flaviviruses: new insights into evolution, pathogenetic determinants and taxonomy. Virology 2007, 361:80-92.

47. D'Agaro P, Martinelli E, Burgnich P, Nazzi F, Del Fabbro S, lob A, Ruscio M, Pischiutti P, Campello C: Prevalence of tick-borne encephalitis virus in Ixodes ricinus from a novel endemic area of North Eastern Italy. J Med Virol 2009, 81:309-316.

48. Kupca AM, Essbauer S, Zoeller G, de Mendonca PG, Brey R, Rinder M, Pfister K, Spiegel M, Doerrbecker B, Pfeffer M, Dobler G: Isolation and molecular characterization of a tick-borne encephalitis virus strain from a new tick-borne encephalitis focus with severe cases in Bavaria, Germany. Ticks Tick Borne Dis 2010, 1:44-51.

49. Carpi G, Bertolotti L, Rosati S, Rizzoli A: Prevalence and genetic variability of tick-borne encephalitis virus in host-seeking Ixodes ricinus in northern Italy. J Gen Virol 2009, 90:2877-2883.

50. Hayasaka D, Suzuki Y, Kariwa H, Ivanov L, Volkov V, Demenev V, Mizutani T, Gojobori T, Takashima I: Phylogenetic and virulence analysis of tick-borne encephalitis viruses from Japan and far-Eastern Russia. J Gen Virol 1999, 80:3127-3135.

51. Uzcategui NY, Sironen T, Golovljova I, Jaaskelainen AE, Valimaa H, Lundkvist A, Plyusnin A, Vaheri A, Vapalahti O: Rate of evolution and molecular epidemiology of tick-borne encephalitis virus in Europe, including two isolations from the same focus 44 years apart. J Gen Virol 2012, 93:786-796.

52. Gäumann R, Ruzek D, Muhlemann K, Strasser M, Beuret CM: Phylogenetic and virulence analysis of tick-borne encephalitis virus field isolates from Switzerland. J Med Virol 2011, 83:853-863.

53. Puchhammer-Stöckl E, Kunz C, Mandl CW, Heinz FX: Identification of tick-borne encephalitis virus ribonucleic acid in tick suspensions and in clinical specimens by a reverse transcription nested polymerase chain reaction assay. Clin Diagn Virol 1995, 4:321-326.

54. Sievers F, Wilm A, Dineen D, Gibson TJ, Karplus K, Li W, Lopez R, McWilliam H, Remmert M, Söding J, Thompson JD, Higgins DG: Fast, scalable generation of high-quality protein multiple sequence alignments using Clustal Omega. Mol Syst Biol 2011, 7:539.

55. Zwickl DJ: Genetic Algorithm Approaches for the Phylogenetic Analysis of Large Biological Sequence Datasets under the Maximum Likelihood Criterion. Austin, US: University of Texas; 2006

56. Tavaré $\mathrm{S}$ : Some probabilistic and the statistical problems in the analysis of DNA sequences. Lect Math Life Sci 1986, 17:57-66.

57. Yang Z: A space-time process model for the evolution of DNA sequences. Genetics 1995, 139:993-1005.

58. Sukumaran J, Holder MT: DendroPy: a Python library for phylogenetic computing. Bioinformatics 2010, 26:1569-1571

59. Wiens JJ: Missing data and the design of phylogenetic analyses. J Biomed Inform 2006, 39:34-42.

60. Avsic-Zupanc T, Poljak M, Maticic M, Radsel-Medvescek A, LeDuc JW, Stiasny K, Kunz C, Heinz FX: Laboratory acquired tick-borne meningoencephalitis: characterisation of virus strains. Clin Diagn Virol 1995, 4:51-59.

61. Pond SLK, Frost SDW, Muse SV: HyPhy: hypothesis testing using phylogenies. Bioinformatics 2005, 21:676-679.

62. Rey FA, Heinz FX, Mandl C, Kunz C, Harrison SC: The envelope glycoprotein from tick-borne encephalitis virus at 2 A resolution. Nature 1995 , 375:291-298.

63. Mukhopadhyay S, Kuhn RJ, Rossmann MG: A structural perspective of the flavivirus life cycle. Nat Rev Microbiol 2005, 3:13-22.

64. Stiasny K, Heinz FX: Flavivirus membrane fusion. J Gen Virol 2006, $87: 2755-2766$ 
65. Chothia C, Lesk AM: The relation between the divergence of sequence and structure in proteins. EMBO J 1986, 5:823-826.

66. Hildebrand A, Remmert M, Biegert A, Soding J: Fast and accurate automatic structure prediction with HHpred. Proteins 2009, 77(Suppl 9):128-132.

67. Biegert A, Mayer C, Remmert M, Soding J, Lupas AN: The MPI Bioinformatics Toolkit for protein sequence analysis. Nucleic Acids Res 2006, 34:W335-W339.

68. Zhang X, Ge P, Yu X, Brannan JM, Bi G, Zhang Q, Schein S, Zhou ZH: Cryo-EM structure of the mature dengue virus at 3.5-A resolution. Nat Struct Mol Biol 2013, 20:105-110.

69. Randolph SE, Asokliene L, Avsic-Zupanc T, Bormane A, Burri C, Gern L, Golovljova I, Hubalek Z, Knap N, Kondrusik M, Kupca A, Pejcoch M, Vasilenko $V$, Zygutiene M: Variable spikes in tick-borne encephalitis incidence in 2006 independent of variable tick abundance but related to weather. Parasit Vectors 2008, 1:44.

70. Bormane A, Lucenko I, Duks A, Mavtchoutko V, Ranka R, Salmina K, Baumanis V: Vectors of tick-borne diseases and epidemiological situation in Latvia in 1993-2002. Int J Med Microbiol 2004, 293(Suppl 37):36-47.

71. Danielova V, Daniel M, Schwarzova L, Materna J, Rudenko N, Golovchenko M, Holubova J, Grubhoffer L, Kilian P: Integration of a tick-borne encephalitis virus and Borrelia burgdorferi sensu lato into mountain ecosystems, following a shift in the altitudinal limit of distribution of their vector, Ixodes ricinus (Krkonose mountains, Czech Republic). Vector Borne Zoonotic Dis 2010, 10:223-230.

72. Holzmann H, Aberle SW, Stiasny K, Werner P, Mischak A, Zainer B, Netzer M, Koppi S, Bechter E, Heinz FX: Tick-borne encephalitis from eating goat cheese in a mountain region of Austria. Emerg Infect Dis 2009, 15:1671-1673.

73. Cotty A: Distribution et fluctuation de populations d'Ixodes ricinus (L.), Haemaphysalis punctata (Can. \& Franz.) et Dermacentor marginatus (Sulzer) (Acarina, Ixodoidea) en Suisse. Bull Société Entomol Suisse 1986, 59:139-150.

74. Burri C, Moran Cadenas F, Douet V, Moret J, Gern L: Ixodes ricinus density and infection prevalence of Borrelia burgdorferi sensu lato along a North-facing altitudinal gradient in the Rhone Valley (Switzerland). Vector Borne Zoonotic Dis 2007, 7:50-58.

75. Rieille N, Bally F, Péter O: Tick-borne encephalitis: first autochtonous case and epidemiological surveillance in canton Valais, Switzerland. Rev Med Suisse 1920, 2012(8):1916-1918.

76. Blaskovic D, Nosek J: The ecological approach to the study of tick-borne encephalitis. Prog Med Virol 1972, 14:275-320.

77. Stefanoff P, Pfeffer M, Hellenbrand W, Rogalska J, Ruhe F, Makowka A, Michalik J, Wodecka B, Rymaszewska A, Kiewra D, Baumann-Popczyk A, Dobler G: Virus detection in questing ticks is not a sensitive Indicator for risk assessment of tick-borne encephalitis in humans. Zoonoses Public Health 2013, 60:215-226.

78. Hubalek Z, Mitterpak J, Prokopic J, Juricova Z, Kilik J: A serological survey for Bhanja and tick-borne encephalitis viruses in sheep of eastern Slovakia. Folia Parasitol (Praha) 1985, 32:279-283

79. Burri C, Korva M, Bastic V, Knap N, Avsic-Zupanc T, Gern L: Serological evidence of tick-borne encephalitis virus infection in rodents captured at four sites in Switzerland. J Med Entomol 2012, 49:436-439.

80. Carpi G, Cagnacci F, Neteler M, Rizzoli A: Tick infestation on roe deer in relation to geographic and remotely sensed climatic variables in a tick-borne encephalitis endemic area. Epidemiol Infect 2008, 136:1416-1424.

81. Klaus C, Hoffmann B, Beer M, Müller W, Stark B, Bader W, Stiasny K, Heinz FX, Süss J: Seroprevalence of tick-borne encephalitis (TBE) in naturally exposed monkeys (Macaca sylvanus) and sheep and prevalence of TBE virus in ticks in a TBE endemic area in Germany. Ticks Tick Borne Dis 2010, 1:141-144.

82. Sikutova S, Hornok S, Hubalek Z, Dolezalkova I, Juricova Z, Rudolf I: Serological survey of domestic animals for tick-borne encephalitis and Bhanja viruses in northeastern Hungary. Vet Microbiol 2009, 135:267-271.

83. Knap N, Korva M, Dolinsek V, Sekirnik M, Trilar T, Avsic-Zupanc T: Patterns of tick-borne encephalitis virus infection in rodents in Slovenia. Vector Borne Zoonotic Dis 2012, 12:236-242.

84. Lindhe KE, Meldgaard DS, Jensen PM, Houser GA, Berendt M: Prevalence of tick-borne encephalitis virus antibodies in dogs from Denmark. Acta Vet scand 2009, 51:56.

85. Achazi K, Ruzek D, Donoso-Mantke O, Schlegel M, Ali HS, Wenk M, Schmidt-Chanasit J, Ohlmeyer L, Rühe F, Vor T, Kiffner C, Kallies R, Rainer GU, Niedrig M: Rodents as sentinels for the prevalence of tick-borne encephalitis virus. Vector Borne Zoonotic Dis 2011, 11:641-647.
86. Klaus C, Beer M, Saier R, Schau U, Moog U, Hoffmann B, Diller R, Süss J: Goats and sheep as sentinels for tick-borne encephalitis (TBE) virus epidemiological studies in areas endemic and non-endemic for TBE virus in Germany. Ticks Tick Borne Dis 2012, 3:27-37.

87. Oehme R, Hartelt K, Backe H, Brockmann S, Kimmig P: Foci of tick-borne diseases in southwest Germany. Int J Med Microbiol 2002, 291(Suppl 33):22-29.

88. Durmisi E, Knap N, Saksida A, Trilar T, Duh D, Avsic-Zupanc T: Prevalence and molecular characterization of tick-borne encephalitis virus in Ixodes ricinus ticks collected in Slovenia. Vector Borne Zoonotic Dis 2010, 11:659-664.

89. Wyler R, Matile H: Tick-borne Encephalitis in Switzerland. Institute of Virology: Zurich; 1984

90. Casati S, Gern L, Piffaretti JC: Diversity of the population of tick-borne encephalitis virus infecting Ixodes ricinus ticks in an endemic area of central Switzerland (Canton Bern). J Gen Virol 2006, 87:2235-2241.

91. Labuda M, Eleckova E, Lickova M, Sabo A: Tick-borne encephalitis virus foci in Slovakia. Int J Med Microbiol 2002, 291(Suppl 33):43-47.

92. Waldenström J, Lundkvist A, Falk Kl, Garpmo U, Bergström S, Lindegren G, Sjostedt A, Mejlon H, Fransson T, Haemig PD, Olsen B: Migrating birds and tickborne encephalitis virus. Emerg Infect Dis 2007, 13:1215-1218.

93. Ernek E, Kozuch O, Lichard M, Nosek J: The role of birds in the circulation of tick-borne encephalitis virus in the Tribec region. Acta Virol 1968, 12:468-470.

94. Hasle G: Transport of ixodid ticks and tick-borne pathogens by migratory birds. Front Cell and Infect Microbiol 2013, 3:48

95. Daniel M, Cerny V, Honzakova E, Olejnicek J: Possibilities of persistence in new biotopes of ticks imported by birds. Folia Parasitol (Praha) 1977 24:47-54.

96. Rizzoli A, Hauffe HC, Tagliapietra V, Neteler M, Rosa R: Forest structure and roe deer abundance predict tick-borne encephalitis risk in Italy. PLoS One 2009, 4:e4336

97. Vogel P, Brönnimann M: Les souris (Mus domesticus) du tunnel du Simplon: leur origine et hypothèses sur leur écologie. Bull Murithienne 2000, 118:33-38.

98. Allison SL, Stiasny K, Stadler K, Mandl CW, Heinz FX: Mapping of functional elements in the stem-anchor region of tick-borne encephalitis virus envelope protein E. J Virol 1999, 73:5605-5612.

99. Altpeter E, Zimmermann H, Oberreich J, Peter O, Dvorak C, Swiss Sentinel Surveillance N: Tick related diseases in Switzerland, 2008 to 2011. Swiss Med Wkly 2013, 143:w13725.

100. Heinz FX, Stiasny K, Holzmann H, Kundi M, Essl A: TBE Epidemiology in Austria. Vienna: Poster presented at ISW TBE; 2014.

\section{doi:10.1186/1756-3305-7-443}

Cite this article as: Rieille et al:: Prevalence and phylogenetic analysis of tick-borne encephalitis virus (TBEV) in field-collected ticks (Ixodes ricinus) in southern Switzerland. Parasites \& Vectors 2014 7:443.

\section{Submit your next manuscript to BioMed Central and take full advantage of:}

- Convenient online submission

- Thorough peer review

- No space constraints or color figure charges

- Immediate publication on acceptance

- Inclusion in PubMed, CAS, Scopus and Google Scholar

- Research which is freely available for redistribution 